\title{
Beban Unit Rekam Medis Paska Sistem Vedika BPJS di RSUD Ungaran
}

\author{
Wulan Kusumastuti*, Ayun Sriatmi*, Septo Pawelas Arso*, Jhovia Aloedya Pramana** \\ *Bagian Administrasi dan Kebijakan Kesehatan, Fakultas Kesehatan Masyarakat, Universitas \\ Diponegoro \\ **Badan Penyelenggara Jaminan Sosial Kantor Cabang Ungaran \\ Email: wulan.kusumastuti@,live.com
}

\section{ABSTRACT}

The implementation of the claim verification (Vedika) digital verification system for advanced level referral health facilities (FKRTL) resulted in the withdrawal of BPJS Health staff / workers in FKRTL giving hospitals. As a result of the implementation of this system, the BPJS Health Center unit which was previously in Ungaran Hospital and has a function as a unit to deal with health service problems for BPJS Health participants is lost. This has an effect on the process of health services in Ungaran Hospital, especially in terms of handling complaints of health services and providing information regarding the participation of BPJS, where the loss of the BPJS Health Center unit has resulted in complaints of health services by BPJS Health patients. In Ungaran Hospital, the function of the BPJS Health Center unit was replaced by the Medical Record unit. The purpose of this study was to analyze the burden of the Medical Record unit at Ungaran Hospital after the implementation of the Vedika system.

Qualitative research methods are presented in descriptive form with study case approach to objectively describe behaviors, perceptions, motivations, and actions.

By using the analysis of the perspective of relatives advantage, compatibility and complexity, the results show that the workload of the Medical
Record unit in the RSUD is increasing because it is charged with the same basic tasks and functions as the BPJS Health Center unit.

Ungaran Hospital requires a policy solution in the form of establishing a new unit to handle complaints about health services and providing information regarding the participation of BPJS Kesehatan to ensure that the rights and obligations of BPJS Health participants are fulfilled.

Keywords: Workload Unit; Health Service; Medical Record Unit

\section{PENDAHULUAN}

Meningkatnya pengetahuan dan kesadaran masyarakat akan kesehatan mengakibatkan tuntutan masyarakat akan mutu pelayanan kesehatan meningkat. Pada era BPJS Kesehatan ini, masyarakat semakin dimudahkan dengan adanya Jaminan Kesehatan Nasional yang dapat menjamin biaya pelayanan kesehatan dengan membayar premi sesuai kelas tertentu setiap bulannya. ${ }^{1}$ Semakin tingginya jumlah kepesertaan BPJS Kesehatan menuntut Rumah Sakit untuk tetap menjaga kualitas dengan kuantitas pasien yang semakin meningkat. Apabila Rumah Sakit tidak mampu menjaga kualitasnya maka akan terjadi permasalahan-permasalahan yang timbul beberapa diantaranya yaitu bisa dari dari 
ketersediaan ruangan, ketersediaan tenaga kesehatan, maupun permasalahan pembiayaan. Permasalahan yang timbul berpotensi pada permasalahan kesenjangan hak dan kewajiban pasien. Hak pasien BPJS Kesehatan adalah pelayanan yang seharusnya didapatkan setelah pasien peserta BPJS Kesehatan menjalankan kewajibannya yaitu membayar premi dan melengkapi persyaratan pelayanan. ${ }^{2}$

Rumah Sakit Umum Daerah Ungaran (RSUD Ungaran) merupakan Rumah Sakit Umum Daerah milik pemerintah daerah Kabupaten Semarang, berada di wilayah Kabupaten Semarang yang terletak di kota Ungaran. RSUD Ungaran merupakan Rumah Sakit rujukan karena menjadi satu-satunya Rumah Sakit Umum yang ada diwilayah kota Ungaran. Tingkat kunjungan pasien di RSUD Ungaran cukup tinggi dimana persentase kunjungan pasien BPJS Kesehatan yaitu sebanyak $80 \%$ dibandingkan dengan pasien umum perharinya. RSUD Ungaran tidak memiliki badan atau unit khusus dalam menangani masalah pelayanan kesehatan pasien peserta BPJS Kesehatan. Hal ini berpotensi terhadap timbulnya keluhankeluhan mengenai pelayanan kesehatan peserta BPJS Kesehatan yang tidak dapat tertangani dengan baik. Terlebih setelah adanya Surat keputusan Direksi No. 78 Tahun 2016 tentang Tim Pilot Project Verifikasi Klaim di Kantor BPJS Kesehatan $^{3}$ yang mengakibatkan adanya pemindahan lokasi dan petugas verifikasi Rumah Sakit yang semula adalah petugas BPJS Kesehatan yang berada di BPJS Kesehatan Center menjadi petugas verifikator dari Rumah Sakit yang telah dilatih saja, sehingga apabila ada permasalahan yang berkaitan dengan pasien peserta BPJS Kesehatan tidak dapat ditangani langsung oleh BPJS Kesehatan Center dan menjadi tanggung jawab Rumah Sakit. Semenjak adanya penarikan petugas BPJS Kesehatan dari RSUD Ungaran pada bulan Maret 2018, sampai saat ini RSUD Ungaran belum memiliki unit baru sebagai pengganti BPJS Kesehatan Center. Apabila terdapat keluhan atau aduan atas pelayanan kesehatan oleh pasien peserta BPJS Kesehatan maka akan ditangani oleh Bidang Rekam Medis.

Ketika terdapat ketidakpuasan atau keluhan atas hak pelayanan terhadap pasien peserta BPJS Kesehatan oleh Rumah Sakit, maka pasien tidak mendapatkan hak yang seharusnya diterima sebagai peserta BPJS Kesehatan sehingga akan merugikan pasien. Rumah Sakit berkewajiban untuk memberikan pelayanan sesuai dengan hak serta memberikan rasa aman kepada pasien, sehingga Rumah Sakit perlu melakukan upaya khusus dalam menanggulangi dan mengantisipasi terjadinya kasus yang mungkin timbul yang berkaitan dengan pelayanan kesehatan pasien peserta BPJS Kesehatan. Segala upaya yang dilakukan oleh Rumah Sakit tersebut juga sebaiknya dilakukan guna mendukung dan memberi informasi kepada pasien peserta BPJS Kesehatan untuk mendapatkan pelayanan kesehatan yang sesuai sehingga tidak terjadi kesenjangan antara hak dan kewajiban yang diterima dan diberikan oleh pasien.

RSUD Ungaran merupakan Rumah Sakit milik pemerintah daerah Kabupaten Semarang dan tidak memiliki badan khusus dalam menangani kasus yang berkaitan dengan tidak terpenuhinya hak pasien khususnya dalam hal pelayanan keluhan pasien peserta BPJS Kesehatan setelah diberlakukannya sistem Vedika yang menghilangkan fungsi dari BPJS Kesehatan Center sehingga penanganan keluhan dan upaya pencerdasan kepada pasien terkait kepesertaan BPJS Kesehatan di Rumah Sakit menjadi tidak terorganisir. Apabila terjadi kasus yang mengakibatkan timbulnya keluhan pasien peserta BPJS Kesehatan karena hak dan kewajibannya tidak terpenuhi maka bidang rekam medik yang akan menangani.

\section{METODE PENELITIAN}

Penelitian ini menggunakan metode penelitian kualitatif dengan pendekatan studi kasus. Penelitian kualitatif adalah penelitian yang dimaksud untuk memahami fenomena tentang apa yang dialami oleh subyek penelitian misalnya perilaku, 
persepsi, motivasi, tindakan, dan lain-lain secara holistik, dan dengan cara deskripsi dalam bentuk kata-kata dan bahasa. ${ }^{4}$

Metode penelitian ini disajikan secara deskriptif dilakukan dengan tujuan utama untuk menyelidiki, menemukan, menggambarkan, dan menjelaskan suatu kegiatan atau keadaan secara obyektif misalnya perilaku, persepsi, motivasi, dan tindakan.

Pihak yang terlibat dalam penelitian ini antara lain informan utama yaitu staf dari bidang atau bagian yang berhubungan erat dengan pelayanan dan Sumber Daya Manusia di RSUD Ungaran. Terdiri dari 1 orang staf rekam medik dan 1 orang kepala sub bagian umum dan kepegawaian dengan teknik pengumpulan data menggunakan metode wawancara mendalam. Dalam penelitian ini dilakukan juga metode triangulasi. Sesuai dengan Patton $^{5}$, teknik triangulasi yang digunakan dalam penelitian ini adalah triangulasi sumber (responden), triangulasi metode (observasi langsung), dan triangulasi teori (membandingkan hasil penelitian dengan teori dan penelitian terkini). Informan triangulasi dalam penelitian ini adalah 1 orang Kepala Bidang Rekam Medik, 1 Orang PIC dan 1 Orang Kepala Seksi Pelayanan Medik.

\section{HASIL DAN PEMBAHASAN}

RSUD Ungaran merupakan salah satu unit pelayanan publik yang ramai dikunjungi oleh pasien di area sekitar sebagai pengguna layanan kesehatan. Sebagai upaya memberikan pelayanan kepada pasien RSUD Ungaran selalu berusaha memberikan pelayanan sebaik mungkin, hal ini berkaitan dengan dicanangkannya program pemerintah bahwa perihal Universal Health Coverage (UHC) yang mana pada tahun 2019 diharapkan seluruh lapisan masyarakat dan seluruh fasilitas kesehatan telah menjadi peserta dan bekerjasama dengan BPJS Kesehatan.

Dalam pelaksanaan kerjasama RSUD Ungaran dengan BPJS Kesehatan masih terdapat berbagai permasalahan yang terkait dengan pelayanan peserta. Beberapa peserta masih mengeluhkan baik dari pelayanan yang diterima atau dari segi biaya pelayanan.

Untuk membantu pasien peserta BPJS Kesehatan mendapatkan apa yang menjadi haknya, terutama setelah ditariknya petugas BPJS Kesehatan dari RSUD Ungaran karena adanya sistem Vedika pada bulan Maret 2018 maka cara penyelesaian keluhan peserta BPJS Kesehatan yang semula dilakukan oleh petugas BPJS Kesehatan yang berada di BPJS Kesehatan Center di RSUD Ungaran dialihkan menjadi tugas beberapa bidang. Berdasarkan hasil wawancara mendalam, didapatkan informasi proses penanganan keluhan peserta BPJS Kesehatan di RSUD Ungaran pada saat ini yaitu dilakukan dengan cara:

1. Secara tidak langsung melalui SMS Center, kotak saran, serta sosial media.

2. Secara langsung dengan menyampaikan keluhannya kepada petugas yang bertanggung jawab di kelas perawatan dan loket pendaftaran rawat jalan.

a. Pada pasien rawat inap, keluhan yang dirasakan pasien peserta BPJS Kesehatan dapat disampaikan langsung kepada penanggungjawab ruangan masing-masing, apabila peserta tidak puas dengan jawaban atau solusi yang disarankan oleh penanggungjawab ruangan, maka penyelesaian akan diserahkan kepada kepala bidang rekam medik. Apabila sampai pada kepala bidang rekam medik peserta tidak juga mendapatkan hasil maka akan diselesaikan oleh pihak manager

b. Pada pasien rawat jalan, keluhan atau permasalahan dapat disampaikan kepada petugas PIC yang bertugas di loket 1 pendaftaran peserta BPJS Kesehatan. Selanjutnya petugas PIC akan meng entry laporan keluhan ke aplikasi SIPP BPJS Kesehatan. Penanganan keluhan seperti denda akan dikirimkan oleh petugas BPJS Kesehatan di kantor BPJS Kesehatan kepada petugas PIC, namun apabila keluhan berupa pelayanan maka petugas PIC tetap meng entry sebagai 
bentuk pelaporan dan penanganan keluhan dilakukan oleh petugas PIC.

Mekanisme pelaporan untuk setiap keluhan yang dilaporkan oleh pasien dilaksanakan oleh masing-masing pihak yang menangani yaitu bidang rekam medik untuk rawat inap, bidang PIC untuk rawat jalan, dan bidang keperawatan untuk aduan yang tidak langsung; sehingga tidak ada laporan kasus aduan yang terpusat yang dapat dijadikan evaluasi baik untuk Rumah Sakit maupun untuk BPJS Kesehatan.

Dalam menentukan beban unit rekam medis di dalam penelitian ini digunakan teori difusi inovasi dari Rogers dimana di dalam teori ini terdapat penelaahan aspek persuasi, dimana terdapat didalamnya mengenai aspek relatives advantages, compatibility dan complexity.

\section{Difusi Inovasi}

Inovasi menurut Rogers adalah gagasan, praktek, atau benda yang dirasa baru oleh suatu individu atau kelompok. Sedangkan difusi diartikan sebagai suatu proses dimana suatu inovasi dikomunikasikan melalui saluran tertentu kepada anggota sasaran suatu sistem dengan jangka waktu tertentu. Sehingga difusi inovasi adalah suatu proses penyampaian dan penyebaran gagasan, praktek, atau benda yang baru dalam upaya untuk merubah suatu masyarakat atau kelompok tertentu yang terjadi secara terus menerus dari suatu tepat ke tempat yang lain, dari suatu waktu ke kurun waktu berikutnya, dan dari suatu bidang tertentu ke bidang yang lainnya kepada suatu kelompok, organisasi, atau sistem sosial. ${ }^{6}$ Tujuan dari dilakukannya difusi inovasi adalah untuk diadopsinya suatu inovasi baik teknologi, ilmu pengetahuan, peraturan atau kebijakan tertentu oleh anggota suatu sistem sosial.

\section{Identifikasi Aspek Persuasi}

Tahap persuasi terjadi ketika individu atau kelompok memiliki sikap positif atau negatif terhadap inovasi sehingga aktif mencari informasi mendalam mengenai inovasi tersebut. Menurut Rogers tahap ini lebih banyak melibatkan adaptor yang berkaitan dengan karakteristik inovasi itu sendiri, yaitu relatives advantage, compatibility, reliability, triability dan observability. Di dalam penelitian ini digunakan identifikasi aspek persuasi teori difusi inovasi Rogers dari tiga aspek yaitu aspek relatives advantage, compatibility dan complexity :

Relatives Advantage (keuntungan relatif) adalah tingkat kelebihan dari suatu inovasi, apakah inovasi tersebut lebih baik dari inovasi yang sudah ada atau yang sudah biasa dilakukan. Keuntungan relatif dapat diukur dari beberapa sisi yaitu ekonomi, kenyamanan, prestasi sosial, dan kepuasan. Semakin besar keuntungan relatif yang dapat dirasakan oleh calon pengguna maka semakin cepat inovasi tersebut dapat diadopsi.

$$
\text { Compatibility (Keserasian) }
$$

adalah keserasian dari sebuah inovasi apakah dapat sesuai dengan nilai-nilai, kebutuhan, dan pengalaman yang ada. Jika motivasi tidak sesuai dengan nilai dan norma yang berlaku pada adopter maka inovasi tersebut tidak dapat atau tidak dapat dengan mudah diadopsi oleh adopter.

Complexity (Kerumitan) dari suatu inovasi sangat berpengaruh dalam penerimaan inovasi oleh calon adopter, seberapa sulit inovasi tersebut dapat diterapkan. Semakin sulit suatu inovasi dapat dipahami oleh calon adopter maka semakin lama inovasi dapat diadopsi.

1) Relatives Advantages (keuntungan relatif)

Keuntungan relatif adalah tingkat kelebihan dari suatu inovasi, apakah inovasi tersebut lebih baik dari inovasi yang sudah ada atau yang sudah biasa dilakukan. Keuntungan relatif dapat diukur dari beberapa sisi yaitu ekonomi, kenyamanan, prestasi sosial, dan kepuasan. Semakin besar keuntungan relatif yang dapat dirasakan oleh calon pengguna maka semakin cepat inovasi tersebut dapat diadopsi. $^{7}$ 
Pada penelitian yang dilakukan oleh Rina Trisnawati $(2017)^{8}$ untuk melihat aspek persuasi dalam karakteristik keuntungan relatif mengenai teknologi E-Paper pada koran solopos. E-paper merupakan sebuah inovasi baru di media cetak yang dianggap lebih efisien untuk digunakan karena tampilannya yang stabil serta bisa didistribusikan ke wilayah yang lebih luas dengan biaya yang lebih rendah. Hal tersebut disimpulkan berdasarkan wawancara mendalam dengan informan.

Pada penelitian ini, untuk melihat karakteristik relatives advantages menilai dari situasi yang ada di RSUD Ungaran, bagaimana sistem penanganan pelayanan kesehatan yang berkaitan dengan pasien peserta BPJS Kesehatan, dan kemungkinan keuntungan atau manfaat dari dibentuknya unit baru bagi pasien BPJS Kesehatan dibandingkan dengan mempertahankan sistem yang ada pada saat ini dimana dibebankan kepada unit rekam medis.

Dari hasil wawancara dengan informan utama dan informan triangulasi didapatkan hasil mengenai bagaimana pelaksanaan sistem penanganan pelayanan kesehatan yang berkaitan dengan pasien peserta BPJS Kesehatan dapat dilakukan dengan beberapa cara. Cara yang dapat dilakukan adalah:

a. Melalui kotak surat dan SMS center yang langsung masuk ke bidang keperawatan kemudian dari bidang tersebut akan meneruskan berdasarkan bidang yang dikeluhkan

b. Rawat jalan, pada pelayanan rawat jalan upaya penanganan dilakukan oleh petugas PIC dengan melakukan entry data keluhan ke SIPP BPJS Kesehatan

c. Rawat inap, untuk pelayanan rawat inap segala keluhan yang berkaitan dengan pelayanan BPJS Kesehatan akan ditangani oleh kepala bidang Rekam Medik
Dari cara-cara tersebut apabila tidak didapatkan hasil yang memuaskan bagi kedua belah pihak maka akan diteruskan di pihak manajemen RSUD Ungaran.

Alur yang telah berjalan berlaku sejak berlakunya Surat keputusan Direksi No. 78 Tahun 2016 tentang Tim Pilot Project Verifikasi Klaim di Kantor BPJS Kesehatan, yang mengubah sistem verifikasi BPJS Kesehatan yang semula dilakukan oleh petugas BPJS Kesehatan di BPJS Kesehatan Center di setiap Rumah Sakit menjadi dilakukan oleh petugas verifikator dari Rumah Sakit dan menghapus BPJS Kesehatan Center, sehingga merubah sistem kerja yang terjadi di Rumah Sakit. Semenjak diberlakukannya Vedika di RSUD Ungaran pada bulan Maret 2018, petugas BPJS Kesehatan tidak lagi berada di Rumah Sakit, sehingga apabila terjadi permasalahan yang bersangkutan dengan peserta BPJS Kesehatan ditangani oleh petugas Rumah Sakit yang diberi tugas tambahan, dalam hal ini unit rekam medis.

Berdasarkan hasil wawancara dengan informan yang terlibat dalam penanganan keluhan oleh peserta BPJS Kesehatan, beliau merasa bahwa beban kerja bertambah karena adanya sistem tersebut sehingga perlu dilakukan pengembangan organisasi dengan menambah atau membentuk unit yang khusus menangani permasalahan BPJS Kesehatan.

Dari hasil wawancara yang dilakukan untuk menggali karakteristik Relatives Advantages (keuntungan relatif) maka dapat disimpulkan bahwa sistem penanganan keluhan yang dilakukan oleh RSUD Ungaran tidak terpusat dan hanya pasien yang mengadu saja yang paham bagaimana alur penanganan, selain itu petugas mengeluhkan mengenai beban kerja yang diterima setelah diberlakukannya sistem Vedika karena pekerjaan yang seharusnya bukan menjadi tanggung 
jawab mereka juga mereka kerjakan. Oleh karena itu diperlukan adanya unit yang khusus menangani permasalahan peserta BPJS Kesehatan agar petugas Rumah Sakit berkerja secara optimal serta pelayanan kepada peserta BPJS Kesehatan menjadi lebih terarah.

2) Compatibility (Keserasian)

$$
\text { Karakteristik }
$$

compatibility

melihat kesesuaian inovasi dengan kebutuhan dan pengalaman yang ada dalam suatu organisasi calon adopter.

Dalam penelitian ini compatibility digali dengan pertanyaan mengenai pengalaman permasalahan yang melibatkan peserta BPJS Kesehatan dengan Rumah Sakit di RSUD Ungaran, kesesuaian dengan visi dan misi RSUD Ungaran, dan kebutuhan Sumber Daya Manusia.

Berdasarkan hasil wawancara dengan informan utama dan di konfirmasi dengan informan triangulasi diperoleh informasi bahwa terdapat beberapa permasalahan mengenai BPJS Kesehatan yang pernah terjadi di RSUD Ungaran yaitu salah satunya adalah kasus pasien peserta BPJS Kesehatan yang ditolak karena tidak memiliki surat rujukan dari fasilitas kesehatan primer ke poli spesialis dan ketidakpuasan pasien dimana pasien merasa keberatan dengan penambahan pembayaran untuk pasien yang naik kelas ke VIP.

Berdasarkan kesesuaian dengan visi dan misi RSUD Ungaran, pembentukan unit baru untuk melayani permasalahan pelayanan kesehatan pasien peserta BPJS Kesehatan dinilai sesuai yaitu untuk mewujudkan pelayanan yang bermutu. Dengan pembentukan unit baru ini maka akan berpengaruh kepada beban kerja, khususnya bagi bidang rekam medis dimana beban kerja akan berkurang sehingga bidang rekam medis yang selama ini diberi pekerjaan tambahan untuk menyelesaikan permasalahan BPJS Kesehatan akan dapat bekerja lebih optimal sesuai dengan tugas pokok dan fungsinya.
Dari hasil wawancara untuk menggali karakter compatibility dapat disimpulkan bahwa RSUD Ungaran memiliki beberapa pengalaman kasus yang berkaitan dengan BPJS Kesehatan dengan begitu apabila dibentuk unit baru yang melayani keluhan pelayanan kesehatan pasien peserta BPJS Kesehatan dinilai sesuai dengan kebutuhan serta visi dan misi RSUD Ungaran.

3) Complexity (kerumitan)

Karakter complexity merupakan tingkat kerumitan dari inovasi. Sebuah inovasi dapat dijalankan oleh calon adopter jika inovasi tersebut mudah untuk dilakukan, apabila inovasi sulit untuk dipahami maka kecenderungan calon adopter untuk mengadopsi semakin sedikit.

Berdasarkan penelitian oleh Reny Puspita (2017) dalam judul Difusi Inovasi E-Paper dalam karakteristik kerumitan, pihak informan menyatakan kendala serta upaya yang dilakukan dalam sosialisasi e-paper yang berbeda-beda. Namun, hambatan yang dialami masih dapat diatasi dengan berbagai strategi yang telah disiapkan oleh petugas sehingga e-paper masih dapat diadopsi. ${ }^{9}$

Dari hasil wawancara dengan informan didapatkan hasil bahwa dengan unit tersebut alur yang dibutuhkan untuk menyelesaikan permasalahan peserta BPJS Kesehatan dinilai akan lebih mudah dan terfokus kepada 1 (satu) bidang saja karena alur pada proses penanganan kasus pada saat ini terkesan sangat menyebar karena terdapat beberapa bidang yang diharuskan untuk terhubung.

Namun kerumitan juga dapat bergantung pada sumber daya yang tersedia, sumber daya yang diharapkan dapat menjadi bagian dari unit baru yang melayani pelayanan kesehatan pasien peserta BPJS Kesehatan diharapkan diisi oleh SDM yang mampu dan berkompeten sehingga dalam proses penyelesaian permasalahan dapat lebih efektif dan 
efisien karena memiliki keunggulan baik dari segi kemampuan menyampaikan informasi dan juga waktu penanganan.

Kemampuan handling complain petugas sangat dibutuhkan dalam unit tersebut karena permasalahan internal yang timbul dari adanya sistem yang berlaku saat ini adalah adanya ketakutan atau culture blaming apabila yang bersangkutan tidak dapat menyelesaikan tugasnya. Hal tersebut mengakibatkan rumitnya penanganan kasus karena adanya rasa takut yang dialami oleh petugas untuk menyerahkan kasus yang tidak bisa ia tangani ke tingkat yang lebih tinggi yaitu manager, sehingga ia mengalihkan kasus tersebut untuk ditangani kepada pihak lain yang belum tentu mengerti.

Berdasarkan hasil wawancara yang dilakukan untuk menggali karakteristik complexity maka didapatkan kesimpulan bahwa kerumitan bergantung pada kemampuan handling complain Sumber Daya Manusia (SDM) yang menangani. Seharusnya apabila sudah dibuat alur yang sedemikian rupa didalam unit baru yang melayani pelayanan kesehatan pasien peserta BPJS Kesehatan maka proses penanganan masalah pelayanan kesehatan akan menjadi lebih fokus, efisien dan efektif.

Mangkuprawira Sjafri mengatakan bahwa dalam suatu organisasi bisnis, unsur manusia menjadi hal yang strategis dalam proses produksi. Bagaimana mengendalikan dan mengelola mereka telah menjadi persoalan sendiri dari suatu organisasi. ${ }^{10}$ Dan dewasa ini kita tahu bahwa perubahan yang semakin meningkat tak mungkin dihindari lagi dalam kehidupan manusia. Sebagai manusia kita hidup dalam dunia yang penuh perubahan ${ }^{11}$.

Ada banyak faktor yang bisa membuat dibutuhkannya tindakan perubahan. Pakar perilaku didalam perusahaan yang dalam bukunya Organizational Behavior yang ditulis oleh
Kreiner Robert dan Kinicki Angelo $(2001)^{12}$ yang dikutip oleh Gunawan R., D., Suryono R., R., dan Purwanto I., (2010) mengatakan bahwa ada dua kekuatan yang dapat mendorong munculnya kebutuhan untuk melakukan perubahan yaitu ${ }^{13}$ : (1) Kekuatan eksternal, yaitu kekuatan yang muncul dari luar organisasi seperti karakteristik demografis (usia pendidikan tingkat keterampilan, jenis kelamin, imigrasi dll. Perkembangan teknologi perubahan-perubahan pasar, tekanantekanan social dan politik; (2) Kekuatan internal, yaitu kekuatan yang muncul dari dalam organisasi, seperti masalah-masalah sumber daya manusia (kebutuhan yang tidak terpenuhi, ketidakpuasan kerja, produktifitas, motivasi kerja dan sebagainya), perilaku dan keputusan manajemen.

Menurut Winardi J., (2010) bahwa perubahan keorganisasian merupakan tindakan berallihnya sesuatu organisasi dari kondisi yang berlaku kini, menuju ke kondisi masa yang akan datang yang diinginkan guna meningkatkan efektivitasnya. Lingkungan keorganisasian terus menerus berubah dan organisasi yang bersangkutan perlu mengadakan perubahan-perubahan agar supaya dapat bertahan ${ }^{14}$.

Hasil penelitian Lianna Sugandi (2012) menunjukkan bahwa suatu organisasi agar tetap dapat survive menghadapi persaingan yang global seperti sekarang ini, sebuah organisasi harus melakukan perubahan tidak terkecuali. Dalam pelaksanaan perubahan dalam organisasi diperlukan adanya sosialisasi yang bertujuan untuk menggambarkan perubahan secara nyata kepada setiap karyawan dan mampu memberikan cermin perubahan untuk dapat dilihat setiap karyawan tentang wujud asli dari perubahan guna menghindarkan terjadinya kebingungan para pegawai dalam mengapresiasikan perilaku dan budaya dalam bekerja serta meminimalisir resistensi yang menjadi penyebab kegagalan dalam melaksanakan perubahan organisasi tersebut. Perubahan dilakukan untuk memberikan dampak positif bagi 
organisasi yang cenderung akan menjadi tantangan yang menarik bagi karyawan yang dapat memahami arah perubahan dalam memberikan respon terhadap perubahan yang terjadi. ${ }^{15}$

\section{KESIMPULAN}

Berdasarkan teori difusi inovasi Rogers pada khususnya menggunakan tinjauan persuasi dengan tiga aspek yaitu relatives advantages, compatibility dan complexity didapat kesimpulan sebagai berikut; dalam aspek Relatives Advantages (Keuntungan Relatif) Sistem penanganan keluhan yang dilakukan oleh RSUD Ungaran tidak terpusat dan hanya pasien yang mengadu saja yang paham bagaimana alur penanganan, selain itu petugas di bagian rekam medis mengeluhkan mengenai beban kerja yang diterima setelah diberlakukannya sistem Vedika karena pekerjaan yang seharusnya bukan menjadi tanggung jawab mereka juga mereka lakukan. Sehingga dirasakan perlunya unit yang khusus menangani permasalahan pelayanan kesehatan peserta BPJS Kesehatan agar petugas Rumah Sakit pada khususnya di bagian unit rekam medis dapat berkerja secara optimal serta pelayanan kepada peserta BPJS Kesehatan menjadi lebih terarah.

\section{Dalam aspek Compatibility} (Keserasian), RSUD Ungaran memiliki beberapa pengalaman kasus yang berkaitan dengan BPJS Kesehatan, dengan begitu apabila dibentuk unit baru yang khusus menangani pelayanan kesehatan pasien peserta BPJS Kesehatan dinilai sesuai dengan kebutuhan serta visi dan misi RSUD Ungaran.

Dari aspek Complexity

(kerumitan), Kerumitan bergantung pada kemampuan handling complain Sumber Daya Manusia (SDM) yang menangani. Seharusnya apabila sudah dibuat alur yang sedemikian rupa dengan membentuk baru yang khusus menangani pelayanan kesehatan pasien peserta BPJS Kesehatan maka proses yang terlaksana dapat menjadi lebih fokus, efisien dan efektif.

Untuk itu, di RSUD Ungaran diperlukan suatu upaya pembentukan bidang atau unit khusus yang baru dalam memenuhi hak pasien sebagai konsumen pelayanan kesehatan sekaligus sebagai peserta Jaminan Kesehatan Nasional oleh Rumah Sakit, hal ini sangat penting mengingat pada tahun 2019 pemerintah menargetkan terciptanya Universal Health Coverage (UHC) sehingga diharapkan seluruh penduduk Indonesia telah terdaftar sebagai peserta BPJS. ${ }^{16}$ Unit khusus tersebut diharapkan dapat menjadi unit preventif atas segala keluhan pelayanan kesehatan pasien peserta BPJS Kesehatan dan juga dapat menjadi unit yang sekaligus menangani keluhan-keluhan ringan sampai dengan mungkin keluhan yang berdampak kepada tindakan penegakan hukum.

Saran bagi RSUD Ungaran adalah diantaranya; Membuat catatan pelaporan kasus terpusat yang sering dikeluhkan oleh peserta BPJS Kesehatan, sehingga dapat menjadi bahan evaluasi bagi pihak Rumah Sakit maupun BPJS Kesehatan, membuat skema atau alur pengaduan keluhan seperti papan petunjuk yang jelas dan di tempatkan pada setiap ruang perawatan, kemudian yang terpenting adalah mempertimbangkan mengenai pembentukan unit baru yang khusus menangani pelayanan kesehatan peserta BPJS Kesehatan sebagai pengganti BPJS Kesehatan Center yang dapat memfasilitasi segala keluhan terkait baik keluhan ringan sampai dengan mungkin keluhan yang dapat menjadi potensi kasus hukum.

\section{DAFTAR PUSTAKA}

1. Premi BPJS yang Harus dibayar Setiap Bulan [Internet]. 2016 [cited 2016 Feb 12]. Available from: https://www.panduanbpjs.com/premibpjs-yang-harus-dibayar-setiap-bulan/

2. Law no 40. Law of the Republic of Indonesia no. 40/2004 regarding The Establishment of a National Social Security System. 2004;1-29.

3. Laporan Pengelolaan Program dan Laporan Keuangan Jaminan Sosial Kesehatan Tahun 2017, BPJS Kesehatan

4. J, Prof. Dr. Lexy Moleong M. Metodologi Penelitan Kualitatif. 
Bandung: PT. Remaja Rosdakarya Offset; 2013. 6 p.

5. Patton, Michael Quinn. Qualitative Evaluation and Research Methods. Newbury Park: Sage Publications, 1990.

6. Rizal F. Penerapan Teori Difusi Inovasi dalam Perubahan Sosial Budaya. 2012; VI(1):130-40.

7. Everett $M$ Rogers. Diffusion of Innovations. New York: The Free Press, 1983.

8. Trisnawati, Rina. Pengaruh Karakteristik Inovasi Terhadap Niat Mengadopsi Solopos Epaper. Universitas Muhammadiyah Surakarta; 2017.

9. Puspitasari L. Difusi Inovasi E-Paper Solopos. Universitas Muhammadiyah Surakarta; 2017.

10. Mangkuprawira, Sjafri. Manajemen Sumber Daya Manusia Strategik. Ghalia. Indonesia: Bogor 2004.

11. Utama, Nang Randu. Perubahan Organisasional Institusi Pendidikan Tenaga Kesehatan. Wineka Media; 2019.

12. Kreitner, Robert. Organizational Behaviour. McGraw-Hill; 2017.

13. Gunawan RD, Suryono RR dan Purwanto. Analisa Perubahan Manajemen dalam Implementasi SI/TI Pada Perguruan Tinggi ABC. SNATI; 2010.

14. J. Winardi. Manajemen Perubahan. Prenada Media Group; 2008.

15. Suhandi, Lianna. Dampak Implementasi Change Management pada Organisasi. Binus University; 2012.

16. JKN Multi Manfaat [Internet]. [cited 2018 Mar 20]. Available from: http://www.depkes.go.id/article/view/1 7060800001/jaminan-kesehatannasional-jkn-.html 